\title{
Academics' use of courseware materials: a survey
}

\author{
Diana Laurillard*, Betty Swift* and Jonathan Darby**
}

* Institute of Educational Technology, Open University, Milton Keynes MK7 6AJ

** CTISS, University of Oxford, 13 Banbury Road, Oxford OX2 6NN

\begin{abstract}
Learning technology has yet to enter the mainstream of higher education. The UFC-funded Teaching and Learning Technology (TLT) programme is attempting to change this by sponsoring projects concerned with courseware production and delivery. These efforts could be thwarted if the Not Invented Here syndrome prevents the use of technology-based teaching and learning materials outside the originating departments. To gain a clearer understanding of why academics have been rejecting much existing courseware, and tó establish the extent of the Not Invented Here syndrome, we carried out a survey of 800 academics in eight UK universities. The survey proved to be exceptionally revealing.
\end{abstract}

\section{Introduction}

The increasing interest in the use of educational technology methods for teaching, fuelled now by the Teaching and Learning Technologies (TLT) programme funding, establishes the creation of such courseware as a widespread academic exercise. This is encouraging for those of us who believe that educational media can enhance student learning and understanding, but it begs the question of who is going to use all the material currently under development. One of the key arguments against course materials as an alternative to lectures has always been the Not Invented Here syndrome: academics are just about prepared to recommend a colleague's textbook, but would not take on video or computer-based teaching material developed elsewhere, as the teaching philosophy would be unlikely to match their own. This is an important argument because the development of course materials, especially computer programs, is economically feasible as a teaching method only if large numbers of student users are likely. Technology-based materials have to travel beyond the originating department, but how can they if the Not Invented Here syndrome applies?

This was the question that exercised the ISC Courseware Development Working Group earlier this year in its deliberations on future mechanisms for universities moving into the field 
(UFC, 1992). We wanted to establish whether the plan to develop materials for use in a range of universities was doomed by academics' preference for in-house teaching. Accordingly, the Working Group designed a questionnaire to investigate the issue among a randomly-selected group of academics. This paper reports on the results.

Little attention has been paid in the past to the attitudes of academic staff in higher education towards the use of computer-based learning (CBL) materials. Researchers trying to identify the factors inhibiting the adoption of courseware have mostly focused their attention elsewhere. Kemeny (1990) sees the problem primarily in terms of the poor quality of available software resulting from the individual, non-collaborative nature of its production. Glick (1990) cites higher education's lack of flexibility and inertia to change as the foremost barrier. Darby (1992) highlights the blockages caused by the secondary importance attached to teaching by the majority of academics (research invariably comes first), the lack of recognition afforded to courseware designers, the limited suitability of much available courseware, and the support problems associated with courseware delivery.

Attitude surveys in higher education have tended to focus on developers (Gardner, 1990), computer centre directors (McDonough, 1991), or university registrars (CSUP, 1992), and have mainly concentrated on technical and resource issues. The Office for Humanities Communication, in its comprehensive survey of computer use in the humanities, surveyed academic departments as well as libraries and computer centres. Referring to responses from academic departments Mullings reports:

Just over half the sample reported problems associated with their use of computers in teaching. These were generally organizational and financial rather than technical. Problems mentioned most frequently were cost, staffing and hardware. (Mullings, 1992)

Several centres in the Computers in Teaching Initiative (CTI) have surveyed academic attitudes in the discipline communities they serve. Hammond et al (1992) report on two such surveys: Land Use and Psychology. Land Use lecturers identified 'lack of time' as the main factor inhibiting their use of computers in teaching. Psychology lecturers were generally positive about computer use but had a narrow perception of potential teaching applications. Indeed Hammond et al note: 'It is likely that some of the respondents were hypothesizing from a state of blissful ignorance.'

\section{The Survey}

The Working Group's survey was designed to find out :

the extent to which academics already use teaching and learning technologies in their teaching

- where the materials being used had originated

- their awareness and opinion of CBL materials in their field, and

- their attitudes to using CBL materials developed elsewhere.

The questionnaire was kept to two sides of straightforward questions, using mainly multiple-choice questions but also generating some open-ended comments (see Appendix). 
The questionnaire was sent to 800 academics selected at random from the Universities Handbook. To minimize costs of mailing, only eight universities were involved in the sample, chosen to represent different types and locations: Aston, Bristol, Cambridge, Glasgow, Hull, University College London, Cardiff, and York. Addressed questionnaires, with covering letters, were sent to a contact at each university for internal circulation to the selected academics. Addressed reminder cards were sent after four weeks, and further copies of the questionnaire with new covering letters were sent after a further four weeks. This elicited a $50 \%$ response rate. Several replies had to be discarded as recipients had changed jobs or status, or were not involved in teaching, giving a usable response rate of $47 \%$.

Quantitative data was coded for computer analysis. Qualitative data, in the form of written open-ended comments, were typed into a computer file, giving some 80 pages of comments. One third were analysed by inspection to produce a range of categories which were then used to categorize the remaining comments. These are described below.

\section{Existing use of teaching and learning technologies}

The great majority of academics recommend textbooks by other authors in their teaching, only 14\% recommending none (Appendix, Question 2). 43\% recommend four or more textbooks as required reading for the three or four courses they are teaching during the year.

Other kinds of educational materials require the use of technology of some kind, either in the classroom or by individual students in a resource centre. Slides were the most popular alternative form, $46 \%$ having used them at some time; videocassettes were next with $35 \%$, then CBL (defined as teaching programs, not just application tools such as word processing or spreadsheets) with $27 \%$. Audio cassettes attracted a much lower response of $11 \%$, perhaps because it is essentially a private study medium, whereas the others can all be class-based and used within lectures (Question 3).

There is a large minority of academics who already make use of teaching and learning technology, therefore, though the proportion using CBL drops to near a quarter. That is partly due to lack of awareness: only $46 \%$ have ever seen CBL programs in their field (Question 4), and only $19 \%$ have had any contact with their CTI centre.

Almost $40 \%$ of the academics using CBL had used only programs originating in their own department or institution (Question 3ii). That is a disturbingly high figure. Individual institutions cannot afford to develop such a high proportion of the CBL programs they need if such programs are to be of good quality, and the medium exploited to its full potential. At present many academics find the programs they need are not available, and develop their own for that reason, which suggests it is a short-term corrective that will change as more courseware becomes available. Or is it a manifestation of the Not Invented Here syndrome? Certainly, there is much criticism of the efforts of others in the field, as the next section below demonstrates.

\section{Attitudes to CBL materials}

Of those in a position to know (i.e. who have seen CBL programs in their field), only $26 \%$ think the majority of them are reasonably good; half find them very mixed in quality 
(Question 4ii). In the written comments on their 'reservations' about computer-based teaching (Question 5), the criticisms voiced tended to focus on the pedagogy rather than on any problems with the accuracy of what was presented:

Much more effort needs to be spent on the user interface. It almost needs to be the focus of development rather than an after-thought.

The present software is designed with idiots in mind. We don't have enough idiots here to make it viable ... [there should be] more emphasis on software being intellectually stimulating.

However, reservations concerning quality of software were very infrequent; there is a sizeable minority who express fundamental concerns about the nature of computer-based teaching in general:

Students can be distanced further from staff members than they are already. This may result in a fundamental misunderstanding of a topic without staff realizing it.

I am strongly against the use of the computer screen as an alternative to hands-on experience with laboratory hardware in such fields as mechanical engineering.

Computers seem inappropriate for material that needs to be pondered over. I would be afraid that they would trivialize the subject, reducing it to a series of responses to problems on the calculation side.

I fear that it would be used as a crutch by students and as an alternative to the work that is required for true understanding.

All these criticisms could be answered with the assurance that computers will not take over, that they will be used only for those parts of the teaching process for which they are suitable, and that they will be properly integrated with the more traditional forms of teacher involvement. These perceptions highlight the importance of clarifying the role computers should take, and confirm its limited nature.

Some clarification of the perceived role can be found in written replies on the 'advantages' of computer-based teaching. The key educational benefits are seen as:

- dynamic visual presentation

- provision for rehearsal of basic skills

- access to data and information sources

- improvement of learning/understanding.

Only the last of these is at all contentious. The category includes achievable expectations such as:

Allows students to progress at their own pace

Students can test themselves as they go along 
It allows students to learn actively without increasing contact time .

Would allow more flexibility and freedom for students to examine process alternatives

with the first being mentioned most frequently, but the category also includes a few optimistic generalities concerning better understanding and help with exploring the subject. No medium can offer these advantages by its very nature; they all need inspired creative input to do that. In general, however, the respondents had a realistic and positive approach to the pedagogic capabilities of computer-based teaching.

\section{The Not Invented Here syndrome}

If at present only a quarter of the university teaching population uses CBL, and only $60 \%$ of the CBL programs an academic uses are developed elsewhere, does this mean that academics are reluctant to take on other people's teaching programs? To gauge the feasibility of a national programme for courseware development, such as TLT, we asked respondents if they would be interested in such collaboration (Question 8a). Interest was high. $52 \%$ of all respondents, not just those who already used CBL, were interested in collaborating with other academics either in their own department or in other institutions in order to develop programs. The inter-university consortium approach to courseware development, advocated by the ISC Working Group (UFC, 1992), and manifested in the TLT call for proposals, was clearly feasible, therefore, as was borne out by the unexpectedly large number of consortium proposals received by the funding council.

That so many academics are now interested in the development of computer-based courseware in their subject is vital for adequate provision of a suitable library of courseware. But the real test of the feasibility of CBL resides also in the preparedness of academics to use courseware originating elsewhere. Again, the responses in the survey were extremely encouraging. Almost $70 \%$ of all respondents were interested in using CBL programs developed by a national programme. Moreover, $60 \%$ of all respondents were interested in evaluating such programs, itself an essential activity if quality of design is to improve.

The survey elicited a fuller picture of attitudes to introducing CBL by asking respondents to react to statements describing different aspects of the issue (Question 6): Around 60\% disagreed with statements that 'a computer-based teaching program would be intrusive' and 'others' ideas would not fit', though $16 \%$ agreed with them, coincident with the proportion who use no textbooks. It is an inevitable consequence of the progress of academic knowledge that at any one time some sizeable proportion of the teaching in universities could and should be promulgated independently of standard texts. That is a figure we cannot expect to change very much. At the same time, many teachers welcome the intrusion of others' ideas, and almost $90 \%$ agree that they would not mind their students being exposed to 'alternative perspectives' on their subject, though this is not the same as alternative 'teaching', which CBL may well embody.

Lack of use of CBL does not reflect its innate unsuitability. Nearly $73 \%$ of respondents agreed that 'some aspects of the subject would benefit from a well-designed computer program'. 
Opinion is exactly balanced when considering the relative merits of CBL. As many agree as disagree that 'limited resources are better spent on other forms of teaching than on computer-based teaching programs', with about $40 \%$ neutral.

The survey shows that while usage of $\mathrm{CBL}$ is still low, at around $25 \%$ of academics, interest is much higher. Most importantly, it counters with impressive evidence the traditional excuse for lack of take-up. The Not Invented Here syndrome is no longer a potent force, if it ever was. The majority of academics are interested in using or testing programs originating elsewhere. There are still barriers to take-up, as the next section describes, but they are logistical and financial, not cultural. Academics, as represented by the respondents to this survey, are open to alternative perspectives in their teaching, aware of the potential benefits of CBL, willing to contribute to its development as a teaching method, but also balanced in their opinion of its relative value.

\section{Academics' concerns}

The radical reconstruction of higher education in the UK is being experienced by academics both as a catalyst for change and as a barrier. Recognition of the former comes from several written comments (Question 8 b). Barriers are seen as 'insufficient time', as pressures in their department make it difficult to take advantage of new teaching methods:

It is very difficult to take a new initiative when one is totally occupied coping with the present demands of the University.

I wish we had more time to develop our teaching, but the demands of academic life make time a virtual impossibility for the foreseeable future. (Strong requirement here is to get on with research).

Given the expansion in student numbers, I would much rather see limited resources available used to increase staff so we can keep class sizes down to maintain teaching quality.

We lost an excellent specialist in this field because of short-sighted administration. Now we have neither the time nor the facilities to use the programs he prepared for us.

Staff time is one problem, 'inadequate resources' is another:

Availability of hardware in sufficient quantity for all students to have enough access.

We simply do not have the resources to utilize computer-based teaching because of the costs of providing hardware to numbers of students who would be involved.

At present we lack the hardware to make use of programs a realistic and regular part of our teaching to $200+$ students per year. 
A related aspect is a concern about the lack of administrative and technical support for the use of CBL:

The main problem is ... maintenance (especially if printers are involved) and general care, up-dating when they become outmoded.

The use of computer programs assumes total efficiency of equipment ... including technicians. This is not necessarily forthcoming.

Use of computers is likely to require substantial demonstrator/teacher support.

Apart from these essentially financial barriers to take-up, many academics raised the more technical/logistical problems of the immutability of software and the lack of standardization on hardware and software platforms. In particular, as subject knowledge develops, how will the updating of courseware be maintained?

[Courseware] developed elsewhere could mean difficulties in adapting to new material or data when it's available.

How would it remain contemporary, i.e. this year's science?

Very fast-moving topic. Every year I update material to reflect new perspectives. Would this be practical with computer-based teaching?

I am teaching in an area that is changing rapidly. Computer-based teaching would only be worthwhile for a few of the basics.

It is in discussing the related problem of customizing software that academics exhibit their reservations about material originating elsewhere:

It is essential that materials developed leave the user free to make additions, deletions and changes, and allow the lecturer to give his/her own start to the material.

Alternative perspectives may be $\mathrm{OK}$, but what is taught must be firmly in the hands of the course organiser ... 'authorware' support is what is needed most.

The ideal computer-assisted teaching program would be customizable by staff as well as interactive with the students, allowing for local preferences.

The solution anticipated in these comments is adaptable courseware, rather than opposition to any form of CBL. Courseware has to adapt not only to teaching, however, but also to hardware and software environments, as many respondents recognized:

The portability issue is also critical - you need portability across (1) machines, (2) operating systems, (3) versions of operating systems, (4) window systems, (5) versions of window systems, (6) other conventions of the environment in which students work. These issues have always seemed prohibitive to me.

It is quite easy to waste time and money developing packages that are not really much use because they are too specific to certain hardware. 
All the points raised in this section are fair comment. UK university teaching is undergoing rapid change, and academics are very aware of the difficulties inherent in making CBL work. All these issues need to be addressed at all levels of the educational system, and on a national basis, if academics are to be persuaded that CBL can go beyond the occasional specialist area into the mainstream of university teaching.

\section{Conclusions}

The survey was able to show that nearly half the university teaching population already use teaching and learning technologies, but only a quarter use CBL. Awareness of CBL is much higher, perhaps due to those who have had contact with their CTI centre, but opinion of what they have seen is mixed. There is a general sense that CBL has some value and could be a lot better. Perhaps because of this, a high proportion of CBL programs originate in the academic's own institution. This is not inevitable, however, as a large majority are interested in using and evaluating materials developed elsewhere.

There is a healthy criticism of existing materials, therefore, but this does not stifle a willingness to collaborate on the development of CBL. Clearly the TLT programme is timely. The danger is that scepticism about what has gone before will lead academics to act as though nothing worthwhile precedes them, and the reinvention of wheels - or worse, the invention of square wheels - will abound, as has happened so often before in this field. The existence of the CTI centres facilitates the grounding of new work in the lessons of the old. The great advantage this bestows on the new TLT programme should not be lost.

The most important message from the survey, however, is the positive one that the Not Invented Here syndrome is not a major influence on British academics considering the use of CBL.

\section{Acknowledgements}

Our thanks are due to the following individuals who assisted in the distribution of the questionnaire in their universities: Sue Furber, Dr Robert Harding, Phil Perkins, June Thompson, Professor Brian Butterworth, Annie Trapp.

\section{References}

CSUP (Committee of Scottish University Principals) (1992), Teaching and Learning in an Expanding Higher Education System, Edinburgh, SCFC.

Darby, J. (1992), 'The future of computers in teaching and learning', Computers in Education, 19, 1/2, 193-197. 
Gardner, N. and Darby, J. (1990), 'Using computers in university teaching: a perspective on key issues', Computers in Education, 15, 1-3, 27-32.

Glick, M.D. (1990), 'Integrating computing into higher education', EDUCOM Review, 25, 2 , 35-38.

Hammond, N., Gardner, N., Heath, S., Kibby, M., Mayes, T., McAleese, R., Mullings, C. and Trapp, A. (1992), 'Blocks to the effective use of information technology in higher education', Computers in Education, 18, 1-3, 155-162.

Kemeny, J.G. (1990), 'Computers in education: progress at a snail's pace', EDUCOM Review 25, 3, 44-47.

McDonough, R.W. (1991), Report of the Working Party on the Provision of Computing Facilities for Teaching, Durham, Inter-University Committee on Computing.

Mullings, C. (1992), Computers and Communication in the Humanities: A Survey of Use, Oxford, OHC.

UFC (Universities Funding Council) (1992), Beyond Lectures: The Report of the Information Systems Committee Courseware Development Working Party, Oxford, CTISS Publications.

(Appendix follows ...) 


\section{Appendix The Use of Courseware Materials}

DL

1 How many courses are you teaching this year? Ring one

None

One

Two

Three

Four or more

$\begin{array}{ll}\text { None } & 1 \\ \text { One } & 2 \\ \text { Two to three } & 3 \\ \text { Four to six } & 4 \\ \text { More than six } & 5\end{array}$

(8)

2 How many textbooks, written by other academics, are you recommending as required reading this year?

3 Have you ever used other kinds of materials developed by other academics in any of your courses? Please ring any you have used

$\begin{array}{lll}\text { Slides } & 1 & (9) \\ \text { Videocassette } & 1 & (10) \\ \begin{array}{l}\text { Audiocassette } \\ \text { Computer-based } \\ \text { teaching programme }\end{array} & 1 & (11) \\ \text { (see Note } 1 \text { below) } & 1 & \\ \end{array}$

Note 1: Not just word-processing packages, empty spreadsheets/databases, calculation tools, analysis tools, programming languages etc.

If you ringed 'computer-based program', where was it (were they) developed? Please ring as appropriate

4 Have you ever seen any computer-based teaching programs in your field? In your department 1 In your institution In the UK Elsewhere 1 1

Yes $\quad 1$

No 2 IF YES: Which of these applies?

The majority are reasonably good 1 The majority are rather poor 2

They are very mixed in quality 3

5 What are your views on the notion of using computer-based teaching program developed elsewhere in your teaching? Please write in relation to one of the courses you teach

Discipline:

Course topic:

Advantages:

Your reservations:

Serious disadvantages/problems: 
6a Still thinking about teaching that particular course and using computer-based teaching programs developed elsewhere, to what extent do you agree with the following? Ring one answer for each item

$\begin{array}{ll}\text { Disagree } & \text { Agree } \\ \text { srrongly } & \text { strongly }\end{array}$

I have my own way of teaching this course, and:

- a computer-based teaching program would be intrusive

- others ideas would not fit

$\begin{array}{lllll}1 & 2 & 3 & 4 & 5\end{array}$

$\begin{array}{lllll}1 & 2 & 3 & 4 & 5\end{array}$

Some aspects of this subject would benefit from a well-designed computer-based teaching program

1

I would not mind my students being exposed to alternative perspectives on this subject to

Limited resources are better spent on other forms of teaching than on computer-based teaching programs

$\begin{array}{llll}2 & 3 & 4 & 5\end{array}$

6b Have you ever had any contact with the Computers in Teaching $\quad$ Yes 1 Initiative (CTI) Centre in your subject area?

IF YES: Please specify the nature of the contact.

7a If a properly funded national consortium was set up to develop computer-based teaching programs in your subject, would you be interested in any of the following? Ring any that apply

- collaborating with academics in your department in developing a program 1

- collaborating with academics in other institutions in developing a program 1

- evaluating programs developed by the scheme

- using programs developed under this scheme

7b Have you any further comments on this issue?

7c Are there particular things you would like to do or see done?

Thank you very much for your help.

Please return your form to the Survey Office, Institute of Educational Technology, the Open University, P O Box 175, Milton Keynes, MK7 6BR. A prepaid label is enclosed. 